\title{
DIVERSIDAD GENÉTICA DE BANANOS Y PLÁTANOS (Musa spp.) DETERMINADA MEDIANTE MARCADORES RAPD
}

\author{
GENETIC DIVERSITY OF BANANAS AND PLANTAINS (Musa spp.) DETERMINED BY RAPD \\ MARKERS
}

\author{
Rocío Nadal-Medina ${ }^{1}$, Gilberto Manzo-Sánchez ${ }^{1 *}$, José Orozco-Romeroº ${ }^{2}$, Mario Orozco-Santos ${ }^{2}$ y \\ Salvador Guzmán-González ${ }^{1}$
}

\begin{abstract}
${ }^{1}$ Laboratorio de Biotecnología, Facultad de Ciencias Biológicas y Agropecuarias, Universidad de Colima. Apartado Postal 36. Autopista Colima-Manzanillo km 40. Tecomán, Colima, México. Tel 01 (313) 32 29405. ² Campo Experimental de Tecomán, Instituto Nacional de Investigaciones Forestales, Agrícolas y Pecuarias. Apartado Postal 88. 28100, Tecomán, Colima, México.
\end{abstract}

*Autor para correspondencia (gmanzo@ucol.mx)

\section{RESUMEN}

La clasificación de germoplasma y la identificación de genotipos de bananos y plátanos (Musa spp.) con los métodos tradicionales (morfológicos) han conducido a tener duplicidad e interpretaciones erróneas. Actualmente la combinación de estas herramientas con métodos moleculares ha clarificado la taxonomía e identificación de genotipos de Musáceas. En este estudio se planteó caracterizar genéticamente a 17 cultivares pertenecientes a cuatro subgrupos genómicos ("Cavendish", "Red", "Plantain", "Ibota" y "Silk") y cinco híbridos de bananos y plátanos, los cuales conforman un banco de germoplasma del Instituto Nacional de Investigaciones Forestales Agrícolas y Pecuarias en Tecomán, Colima, México. Se identificaron 90 marcadores RAPD (polimorfismos en el ADN amplificados al azar) entre las 22 accesiones analizadas, de los cuales 83 fueron polimórficos. Se registró una estrecha relación entre la clasificación morfológica y diversidad molecular detectada entre los subgrupos analizados. El análisis filogenético generó dos grupos diferentes identificados como A y B. El grupo A se conformó por 10 accesiones pertenecientes solamente al subgrupo "Cavendish", y como excepción se integró el híbrido 'FHIA 03'. Al grupo B se integraron accesiones pertenecientes a diferentes subgrupos, los cuales fueron "Red", "Plantain" y "Cavendish", así como los híbridos 'FHIA 01', 'FHIA 20', 'FHIA 2' y 'SH-3640'. Las accesiones 'Yangambi km 5' y 'Manzano' pertenecientes a los subgrupos "Ibota" y "Silk", respectivamente, no se ubicaron en estos dos grupos.

Palabras clave: Musa ssp., diversidad genética, marcadores moleculares.

\section{SUMMARY}

The classification of germplasm and the identification of genotypes of bananas and plantains (Musa spp.) by traditional methods (morphology) are confusing, thus leading to duplicity and erroneous interpretations. Currently, the combination of morphological features with molecular tools has clarified the taxonomy and identification of Musacea genotypes. In this study, 22 accessions of bananas and plantains of different subgroups ("Cavendish", "Red", "Plantain", "Ibota" and "Silk") and some synthetic hybrids were mor- phologically and genetically characterized. These accessions belong to the germplasm bank of the Instituto Nacional de Investigaciones Forestales Agrícolas y Pecuarias located at Tecomán, Colima, México. Ninety randomly amplified polymorphic DNA (RAPD) markers from the 22 accessions were identified, of which 83 were polymorphic. A correlation between the morphological classification and molecular diversity among the different subgroups was found. The dendrogram generated showed two groups: Group A had 10 accessions from the "Cavendish" subgroup plus the hybrid "FHIA 03'. Group B clustered accessions belonging to subgroups "Red", "Plantain" and "Cavendish", as well as hybrids 'FHIA 01', 'FHIA 20', 'FHIA 21' and 'SH-3640'. Accessions 'Yangambi km 5' and 'Manzano', which belong to subgroups "Ibota" and "Silk" respectively, were not found in any of these two groups.

Index words: Musa spp., genetic diversity, molecular markers.

\section{INTRODUCCIÓN}

Los bananos y plátanos son monocotiledóneas de porte alto, originadas de cruzas intra e inter-específicas entre Musa acuminada Colla (genoma A) y Musa balbisiana Colla (genoma B) que pertenecen a la familia Musaceae. Estas especies diploides provienen de los genomas A y B, respectivamente (Simmonds y Shepherd, 1955; Simmonds, 1962). En orden de importancia económica, existen bananos triploides ( $\mathrm{AAA}, \mathrm{AAB}$ y $\mathrm{ABB}$ ), diploides (AA y $\mathrm{AB}$ ) y tetraploides (AAAA, AAAB y AABB). Los principales cultivares comerciales son triploides, altamente estériles, partenocárpicos y propagados asexualmente (Simmonds y Shepherd, 1955; Simmonds, 1962; Ortiz y Vuylsteke, 1996). Los bananos y plátanos representan el principal alimento de al menos 400 millones de personas. Anualmente se producen 85.5 millones toneladas y alrededor de $10 \%$ se exporta para consumirse como postre (Ortiz y Vuylsteke, 1996). 
La industria del banano para exportación es importante en la economía de países de América Latina y del Caribe, Asia y África (Simmonds y Shephered, 1955; Ortiz y Vuylsteke, 1996). Desde la década de los 90's se ha intentado reforzar la investigación del cultivo, enfocada principalmente al mantenimiento de los bancos de germoplasma y al mejoramiento genético por métodos convencionales y no convencionales (Ortiz, 1995; Rout et al., 2000). Los marcadores moleculares se han utilizado para analizar la diversidad genética y en la organización e identificación de bancos de germoplasma de algunas $\mathrm{Mu}$ sáceas, y sus resultados indican que la mayoría de cultivares de banano y plátano tienen un elevado nivel de similitud genética entre cultivares de la misma especie (Grapin et al., 1998; Pillay et al., 2000; Wong et al., 2002; Ude et al., 2003).

Durante los últimos años los fitomejoradores han implementado el uso de las características morfológicas y moleculares para registrar y proteger algunas colecciones de interés agrícola (Staub et al., 1996; Vuylsteke et al., 1997). A principios de la década de los 90 's se iniciaron los estudios moleculares en Musáceas, mediante varios tipos de marcadores de ADN como RFLP (polimorfismo de la longitud de fragmentos de restricción) (Bhat et al., 1995), RAPD (polimorfismos en el ADN amplificado al azar) (Bhat et al., 1995; Kaemmer et al., 199 2; Howell et al., 1994; Damasco et al., 1996), secuencias simples repetitivas (SSR) (Grapin et al., 1998; Crouch et al., 1998) y recientemente AFLP (polimorfismo de la longitud de fragmentos amplificados) (Wong et al., 2002; Ude et $a l ., 2002 ; 2003)$. Los marcadores RFLP son laboriosos y consumidores de tiempo para aplicaciones rutinarias. En cambio, los SSR son altamente polimórficos y se basan en la PCR (reacción en cadena de la polimerasa), pero sus principales desventajas son el alto costo y la necesidad de un conocimiento previo de la secuencia del genoma. Por su parte, los AFLP son capaces de producir un gran número de marcadores en un corto tiempo, y se basan en la amplificación selectiva de la PCR de fragmentos restringidos, pero también con un alto costo (Staub et al., 1996). Los marcadores RAPD son de menor costo y fáciles de laborar, no es necesario un conocimiento previo de la secuencia del genoma y consumen poco tiempo (Williams et al., 1990).

Los marcadores RAPD se han empleado en la identificación, clasificación y caracterización de bancos de germoplasma de bananos y plátanos silvestres, cultivares, híbridos y mutantes inducidos (Bhat et al., 1995; Kaemmer et al., 1992; Howell et al., 1994; Ude et al., 2003). También han proporcionado información para identificar variantes somaclonales inducidos por el cultivo in vitro
(Damasco et al., 1996) y marcadores ligados a la secuencia de los genomas A y B (Pillay et al., 2000).

Los análisis genéticos moleculares proporcionan información precisa para clasificar taxonómicamente y determinar grupos filogenéticos, los cuales son valiosos para identificar accesiones duplicadas, así como para el registro, protección y definición de colecciones de Musáceas (Ortiz y Vuylsteke, 1996). Acorde con la dispersión geográfica, es común la práctica de conferir nombre locales a los cultivares con base en las características de la fruta y de la planta, lo que origina una confusión de sinónimos y problemas para colectar, identificar y clasificar cultivares (Ortiz y Vuylsteke, 1996; Vuylsteke et al., 1997).

La clasificación morfológica de bananos y plátanos se basa principalmente en 100 características, algunas de las cuales son: altura y color del pseudotallo; naturaleza de la hoja; color, forma y posición del estigma; tipo y orientación del racimo; longitud del pedúnculo; forma, tamaño, número y curvatura de la fruta; y presencia de semillas (Simmonds y Shepherd, 1955; Swennen y Vuylsteke, 1987; IPGRI-INIBAP/CIRAD Descriptor, 1996). Pero las características morfológicas dependen de la interacción genotipo $\mathrm{x}$ ambiente, que las hacen inestables y variables entre años y localidades geográficas, lo cual limita su uso en la taxonomía de Musáceas (Vuylsteke et al., 1997; Ude et al., 2002). Además, las características morfológicas son usualmente determinadas por un pequeño número de genes que podrían no representar la diversidad genética total, y pueden ser engañosas para su interpretación (Staub et al., 1996; Pillay et al., 2000; Wong et al., 2002; Ude et al., 2003). Por tanto, los agrupamientos taxonómicos basados en descriptores morfológicos no podrían determinar con precisión las relaciones entre las accesiones. Lo anterior, demuestra la necesidad de utilizar las herramientas moleculares para tener mayor precisión en la clasificación de las accesiones de los bancos de germoplasma. El objetivo del presente trabajo fue caracterizar, mediante marcadores moleculares de ADN, los materiales de bananos, plátanos y algunos híbridos que conforman el banco de germoplasma del Instituto Nacional de Investigaciones Forestales, Agrícolas y Pecuarias (INIFAP), localizado en el Campo Experimental de Tecomán, Colima, México.

\section{MATERIALES Y MÉTODOS}

\section{Material vegetativo}

El banco de germoplasma está formado por varios tipos de bananos, plátanos y algunos híbridos, aquí nombrados todos como accesiones (Cuadro 1), a las cuales se ha estudiado su adaptación, desempeño de producción y 
resistencia a plagas y enfermedades en las condiciones del trópico seco de México. Estas plantas se han mantenido en condiciones de campo durante 12 años. La plantación se riega por inundación (rodado) cada $18 \mathrm{~d}$. No se aplica control químico alguno de plagas y enfermedades. Anualmente, se fertiliza con una dosis $200 \mathrm{~N}-75 \mathrm{P}-150 \mathrm{~K}$. El suelo es franco arcilloso con $\mathrm{pH}$ alcalino, bajo contenido de nitrógeno y fósforo, y alta cantidad de carbonato de calcio. Se colectó la hoja más joven (hoja cigarro) de plantas en etapa de producción, de cada una de las 22 accesiones; las hojas se limpiaron con etanol $70 \%$ y se almacenaron dentro de bolsas de plástico a $-80^{\circ} \mathrm{C}$, según Crouch et al. (1998).

\section{Extracción del ADN genómico}

La extracción del ADN genómico de las 22 accesiones se hizo con la metodología descrita por Doyle y Doyle (1990) con algunas modificaciones. De cada hoja cigarro se tomaron $0.3 \mathrm{~g}$ que se molieron con un mortero con pistilo estéril en presencia de $\mathrm{N}_{2}$ líquido. El ADN genómico se resuspendió en 60 a $80 \mu \mathrm{L}$ de amortiguador TE $(10$ $\mathrm{mM}$ Tris $\mathrm{HCl} \mathrm{pH} 8.0 ; 1$ mM EDTA pH 8.0) y se verificó su calidad en gel de agarosa $0.8 \%$ teñido con bromuro de etidio $\left(10 \mu \mathrm{g} \mathrm{mL}^{-1}\right)$. Se efectuaron al menos dos extracciones de ADN independientes de cada accesión.

\section{Determinación de marcadores RAPD}

Inicialmente se analizaron 10 accesiones ('Enano Gigante', 'Valery', 'Rambao', 'FHIA 01', 'FHIA 03', 'FHIA 21', 'Yangambi km 5', 'Manzano', 'Robusta' y 'Dwarf Lacatán') del germoplasma, con el empleo de 21 combinaciones de oligonucleótidos decámeros, mediante la metodología descrita por Williams et al. (1990); de éstas se seleccionaron las ocho combinaciones que dieron el mayor número de bandas amplificadas y polimórficas, por ser reproducibles en amplificaciones independientes y repetibles en las diversas extracciones de ADN (Cuadro 2). Para obtener los marcadores RAPD se utilizó un volumen de reacción de $25 \mu \mathrm{L}$, que contenía $50 \mathrm{ng}$ de $\mathrm{ADN}, 2.5$ $\mathrm{mM}$ de $\mathrm{MgCl}_{2}, 200 \mathrm{mM}$ de Tris- $\mathrm{HCl} \mathrm{pH} 8.4,500 \mathrm{mM}$ de $\mathrm{KCl}, 200 \mathrm{mM}$ de la mezcla de nucleótidos trifosfatados (dNTP's), $0.5 \mu \mathrm{M}$ de cada oligonucleótido decámero (GIBCO BRL, Maryland, USA), 0.5 U de Taq ADN polimerasa (GIBCO BRL), y agua bidestilada y esterilizada para aforar a un volumen final de $25 \mu \mathrm{L}$. La PCR se llevó a cabo en un termociclador (Applied Bioscience 9600) con la metodología propuesta por Williams et al. (1990): ciclo 1: $94{ }^{\circ} \mathrm{C}$ por $5 \mathrm{~min} ; 36{ }^{\circ} \mathrm{C}$ por $1 \mathrm{~min} ; 72{ }^{\circ} \mathrm{C}$ por $4 \mathrm{~min}$; ciclos 2-35: $94{ }^{\circ} \mathrm{C}$ por $1 \mathrm{~min}, 36{ }^{\circ} \mathrm{C}$ por $1 \mathrm{~min} ; 72{ }^{\circ} \mathrm{C}$ por 4 min. Después de la PCR los productos amplificados se separaron mediante electroforesis en geles de agarosa
$1.4 \%(\mathrm{p} / \mathrm{v})$. Posteriormente, los productos amplificados fueron visualizados y captados con la ayuda del sistema Eagle Eye II (Stratagene), después de ser teñidos con bromuro de etidio $\left(10 \mu \mathrm{g} \mathrm{mL}^{-1}\right)$.

\section{Análisis de los datos}

Las variables cualitativas se analizaron con base en la presencia (indicada por 1) o la ausencia (por un 0) de bandas amplificadas en cada combinación de oligonucleótidos decámeros. Los datos se procesaron con la ayuda del programa S-Plus Versión 4.0 (S-Plus, 1997). La similitud genética entre dos muestras, A y B, se determinó por el método de Nei y Li (1979) de la siguiente manera: $S_{A B}=$ $2 N_{A B} /\left(N_{A}+N_{B}\right)$, donde $N_{A B}=$ número de bandas identificadas entre A y B, $N_{A}=$ número de bandas presentes en A, y $N_{B}=$ número de bandas presentes en B. Los análisis de agrupamiento se hicieron sobre la relación de matrices con el método de promedio aritmético de grupos de pares no ponderados (siglas en inglés, UPGMA) (Avise, 1994). El método de Felsenstein se aplicó para obtener el intervalo de confianza para los grupos formados en cada nodo del dendrograma, por lo cual se hizo un análisis de muestreo con reemplazo ("Bootstrapping", 3000 repeticiones) de los datos originados de los marcadores RAPD, con la finalidad de obtener datos numéricos del dendrograma estadísticamente más robusto.

\section{RESULTADOS Y DISCUSIÓN}

\section{Análisis de marcadores RAPD}

El típico patrón de bandas de marcadores RAPD generado en este estudio se presenta en la Figura 1, en la cual se aprecian los productos generados por la combinación de los oligonucleótidos decámeros OPC15 y A01, con 10 marcadores polimórficos obtenidos entre las 22 accesiones de bananos y plátanos. Cada combinación de oligonucleótidos decámeros generó un rango de ocho (con la combinación M04 y OPA03) a 15 bandas amplificadas (con la combinación OPA04 y PLAT), lo que significa de 62.5 a $100 \%$ de bandas polimórficas entre las 22 accesiones, para un total de 90 bandas amplificadas, de las cuales $92.2 \%$ fueron polimórficas (Cuadro 2). Kaemmer et al. (1992) reportaron que al hacer combinaciones de dos oligonucleótidos decámeros se obtenía mayor número de bandas polimórficas (ocho bandas) en bananos, que con un solo oligonucleótido (tres bandas). En cambio, Damasco et al. (1996) reportaron de 1 a 10 bandas por oligonucleótido en plantas micropropagadas normales y chaparras de los cultivares 'Nueva Guinea' y 'Williams' (subgrupo "Cavendish"). Por su parte, Howell et al. (1994) reportaron un rango de 2 a 20 bandas amplificadas por iniciador en un banco de germoplasma de Musa spp. compuesto por 
los genomas AA, AAA, AAB, ABB y BB. Se considera aceptable el hecho de que con ocho combinaciones de iniciadores decámeros se hayan obtenido resultados en cuan- to al polimorfismo, ya que en otras investigaciones se ha usado una menor cantidad de iniciadores decámeros (Kaemmer et al., 1992).

Cuadro 1. Características generales de las 22 accesiones de Musa spp. pertenecientes a un banco de germoplasma del Instituto Nacional de Investigaciones Forestales Agrícolas y Pecuarias en Tecomán, Colima, analizadas mediante marcadores RAPD.

\begin{tabular}{|c|c|c|c|c|c|c|c|c|c|c|c|}
\hline \multirow{2}{*}{$\begin{array}{l}\text { Nombre } \\
\text { común }\end{array}$} & \multirow{2}{*}{ Subgrupo } & \multirow{2}{*}{ Genoma } & \multirow{2}{*}{$\begin{array}{l}\text { Forma de } \\
\text { consumo }\end{array}$} & \multirow{2}{*}{$\begin{array}{c}\text { Altura de } \\
\text { planta (m) }\end{array}$} & \multirow{2}{*}{$\begin{array}{c}\text { Color del } \\
\text { pseudotallo }\end{array}$} & \multicolumn{6}{|c|}{ Reacción a } \\
\hline & & & & & & $\mathrm{SN}$ & MP & $\mathrm{N}$ & $\mathrm{P}$ & VBT & MB \\
\hline 'Cocos A' & "Cavendish" & AAA & Ps & 2.0 & Verde medio & $\mathrm{S}$ & $\mathrm{S}$ & $S$ & $\mathrm{~S}$ & $\mathrm{~S}$ & $\mathrm{~S}$ \\
\hline 'Cocos B' & "Cavendish" & AAA & Ps & 2.0 & Verde & $\mathrm{S}$ & $\mathrm{S}$ & $\mathrm{S}$ & $\mathrm{S}$ & $\mathrm{S}$ & $\mathrm{S}$ \\
\hline 'Enano 1' & "Cavendish" & AAA & Ps & 2.0 & Verde amarillo & $\mathrm{S}$ & $\mathrm{S}$ & $S$ & $\mathrm{~S}$ & $\mathrm{~S}$ & $\mathrm{~S}$ \\
\hline 'Enano 2' & "Cavendish" & AAA & Ps & 2.0 & Verde amarillo & $\mathrm{S}$ & $\mathrm{S}$ & $\mathrm{S}$ & $\mathrm{S}$ & $\mathrm{S}$ & $\mathrm{S}$ \\
\hline 'Enano Chaparro' & "Cavendish" & AAA & Ps & 1.8 & Verde & $\mathrm{S}$ & $\mathrm{S}$ & $\mathrm{S}$ & $\mathrm{S}$ & $S$ & $\mathrm{~S}$ \\
\hline 'Enano Gigante' & "Cavendish" & AAA & Ps & 2.0 & Verde amarillo & $\mathrm{S}$ & $\mathrm{S}$ & $S$ & $\mathrm{~S}$ & S & $\mathrm{S}$ \\
\hline 'Valery' & "Cavendish" & AAA & Ps & 2.7 & Verde & $\mathrm{S}$ & $\mathrm{S}$ & $S$ & $\mathrm{~S}$ & S & $\mathrm{S}$ \\
\hline 'Rambao' & "Cavendish" & AAA & Ps & 2.0 & Verde & $\mathrm{S}$ & $\mathrm{S}$ & $\mathrm{S}$ & $\mathrm{S}$ & $\mathrm{S}$ & $\mathrm{S}$ \\
\hline 'Golden Beauty' & "Cavendish" & AAA & Ps & 2.0 & Verde amarillo & $\mathrm{S}$ & $\mathrm{S}$ & $\mathrm{S}$ & $\mathrm{S}$ & $S$ & $\mathrm{~S}$ \\
\hline 'Robusta A' & "Cavendish" & AAA & Ps & 2.0 & Verde & $\mathrm{S}$ & $\mathrm{S}$ & $\mathrm{S}$ & $\mathrm{S}$ & $S$ & $\mathrm{~S}$ \\
\hline 'Robusta B' & "Cavendish" & AAA & Ps & 2.0 & Verde & $\mathrm{S}$ & $\mathrm{S}$ & $\mathrm{S}$ & $\mathrm{S}$ & $S$ & $\mathrm{~S}$ \\
\hline 'Dwarf Lacatán' & "Cavendish" & AAA & Ps & 2.0 & Verde amarillo & $\mathrm{S}$ & $\mathrm{S}$ & $\mathrm{S}$ & $\mathrm{S}$ & $S$ & $\mathrm{~S}$ \\
\hline 'Morado' & "Red" & AAA & Ps y Coc & 2.0 & Rojo-verde & $\mathrm{T}$ & $\mathrm{S}$ & $\mathrm{S}$ & $\mathrm{S}$ & & \\
\hline 'Norteño' & "Red" & AAA & Ps y Coc & 2.7 & Verde & $\mathrm{S}$ & $\mathrm{S}$ & $S$ & $\mathrm{~S}$ & & \\
\hline 'Macho' & "Plantain" & $\mathrm{AAB}$ & Coc & 2.0 & Verde & $\mathrm{S}$ & $\mathrm{S}$ & $S$ & & & \\
\hline 'Manzano' & “Silk” & $\mathrm{AAB}$ & Ps & 2.7 & Amarillo & $\mathrm{S}$ & $\mathrm{S}$ & $S$ & & & \\
\hline 'Yangambi km 5' & "Ibota" & AAA & Ps y Coc & 2.0 & Verde con manchas negras & $\mathrm{R}$ & $\mathrm{R}$ & $\mathrm{S}$ & $\mathrm{R}$ & $\mathrm{R}$ & \\
\hline 'FHIA 01' & & AAAB & Ps y Coc & 2.7 & Verde amarillo & $\mathrm{R}$ & $\mathrm{R}$ & $\mathrm{S}$ & & & \\
\hline 'FHIA 03' & & AABB & $\mathrm{Coc}$ & 2.5 & Verde & $\mathrm{T}$ & $\mathrm{R}$ & $S$ & & & \\
\hline 'FHIA 20' & & $\mathrm{AAAB}$ & $\mathrm{Coc}$ & 2.7 & Verde amarillo & $\mathrm{R}$ & $\mathrm{R}$ & $\mathrm{S}$ & & & \\
\hline 'FHIA 21' & & AAAB & $\mathrm{Coc}$ & 2.5 & Verde amarillo & $\mathrm{R}$ & $\mathrm{R}$ & $\mathrm{S}$ & & & \\
\hline 'SH-3640' & & AAAB & $\mathrm{Coc}$ & 2.0 & Verde amarillo & $\mathrm{S}$ & $\mathrm{S}$ & $S$ & & & \\
\hline
\end{tabular}

Según normas establecidas en: Descriptors for bananas (Musa spp.) (IPGRI-INIBAP/CIRAD, 1996). Porte bajo: $\leq 2 \mathrm{~m}$, porte medio o normal: 2.1 a $2.9 \mathrm{~m}$ y porte alto: $\geq 3.0 \mathrm{~m}$. $\mathrm{S}=$ Sigatoka negra; $\mathrm{MP}=$ Mal de Panamá; $\mathrm{N}=$ Nemátodos; $\mathrm{P}=$ Picudo; $\mathrm{VBT}=$ Virus del "bunchy top"; MB = Moko bacteriano; Ps = Postre; Coc $=$ Cocción; $\mathrm{R}=$ Resistente; $\mathrm{T}=$ Tolerante; $\mathrm{S}=$ Susceptible.

Cuadro 2. Combinaciones de oligonucleótidos decámeros bandas amplificadas, bandas polimórficas y porcentaje de polimorfismo determinado entre las 22 accesiones de Musa spp.

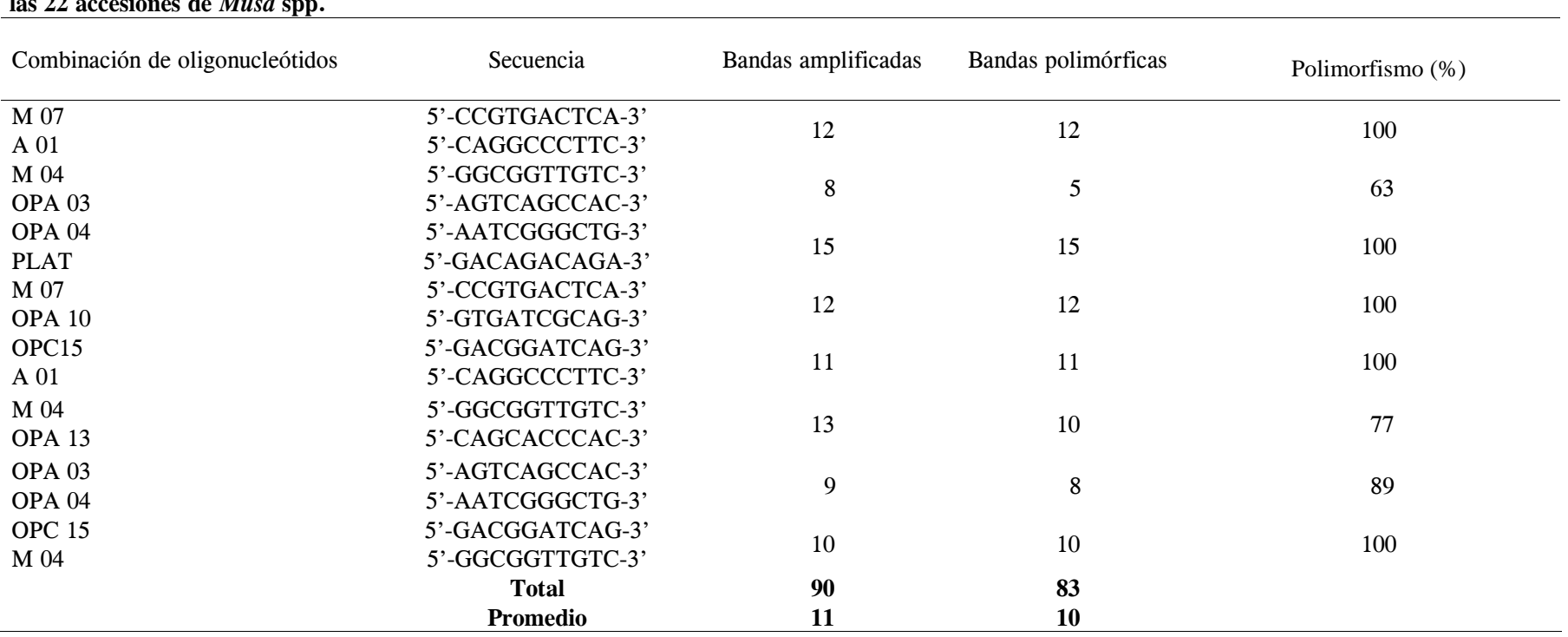




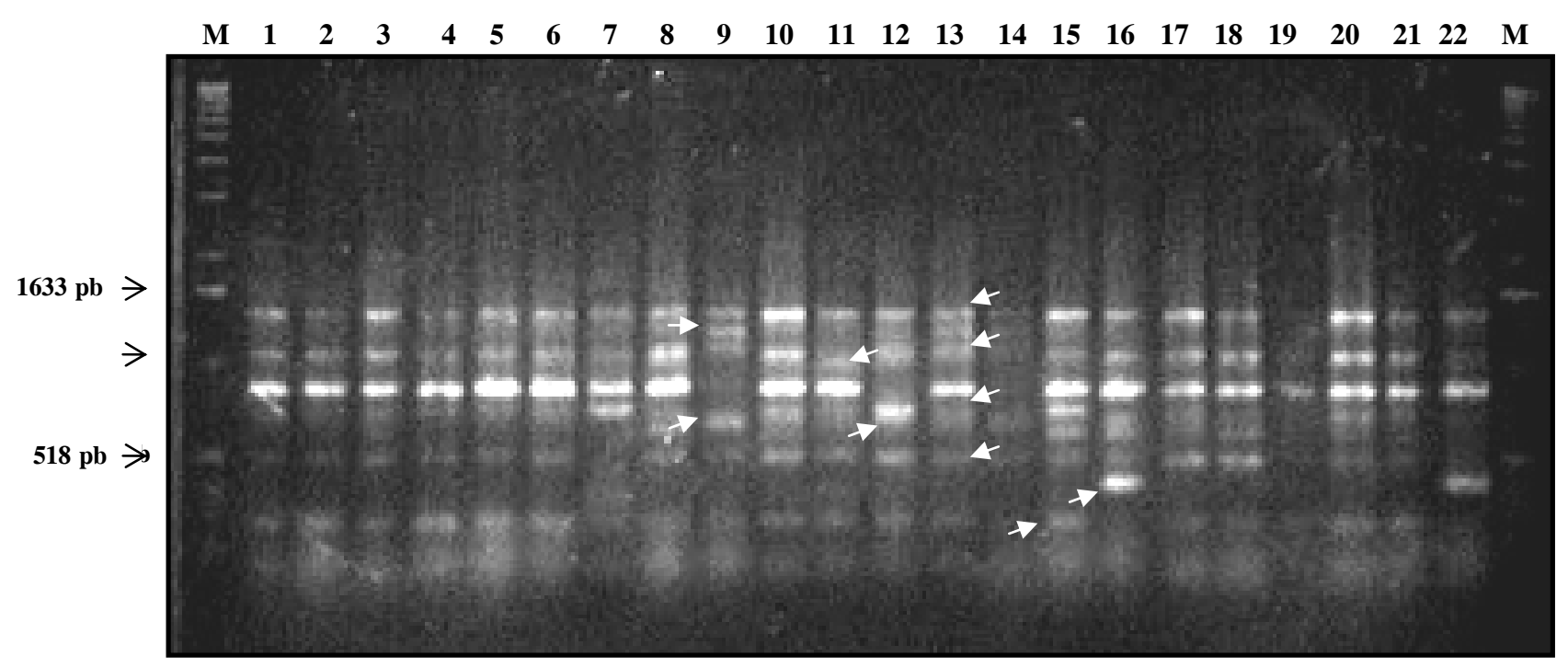

Figura. 1. Amplificación de marcadores RAPD producidos por la combinación de los oligonucleótidos decámeros OPC 15 (5’-GACGGATCAG-3’) y A 01 (5'-CAGGCCCTTC-3') en 22 accesiones de Musa spp. Carriles M: marcadores de peso molecular (1 kb ladder, GIBCO BRL); 'Cocos A' (carril 1); 'Cocos B' (carril 2); 'Enano 1' (carril 3); 'Enano 2' (carril 4); 'Enano Chaparro' (carril 5); 'Enano Gigante' (carril 6); 'Manzano' (carril 7); 'Morado' (carril 8); 'Macho' (carril 9); 'Valery' (carril 10); 'FHIA 01' (carril 11); 'FHIA 03' (carril 12); 'FHIA 20' (carril 13); 'FHIA 21' (carril 14); 'HS-3640' (carril 15); 'Yangambi km 5' (carril 16); 'Rambao' (carril 17); 'Norteño' (carril 18); 'Golden Beauty' (carril 19); 'Robusta A' (carril 20); 'Robusta B' (carril 21) y 'Dwarf Lacatán' (carril 22). Los productos amplificados de la PCR fueron analizados en gel de agarosa 1.4\% y teñidos con bromuro de etidio. Las flechas indican los marcadores polimórficos.

\section{Relaciones genéticas entre las accesiones de Musa spp.}

Los análisis de agrupamiento de los 90 marcadores RAPD por el método de apareamiento simple, promedio y con 3000 repeticiones, produjo un dendrograma en el que se pueden apreciar claramente dos grupos (grupo A y grupo B), los cuales encierran características morfológicas semejantes entre los individuos que los conforman (Figura 2). En el grupo A se observaron 10 accesiones ('Enano Chaparro', 'Enano 1', 'Enano 2', 'Enano Gigante', 'Co$\cos$ A', 'Cocos B', 'Dwarf Lacatán', 'Golden Beauty', 'Robusta A' y 'Robusta B') que pertenecen al subgrupo "Cavendish", todo ellos son triploides AAA que se usan para postre y se consumen en estado fresco (Daniells et $a l ., 2001)$. La mayoría de éstos son de uso comercial por el sabor dulce de su fruta, con racimos delgados pero dedos gruesos, de porte bajo (muy bajo, como en el caso del 'Enano Chaparro') a medio, pseudotallo grueso y de color verde, y son susceptibles a Sigatoka negra (Mycosphaerella fijiensis $\mathrm{M}$. Morelet).

Se han reportado casos similares en donde los genomas AAA muestran disimilitud genética con los genomas AAB y ABB (Howell et al., 1994; Kaemmer et al., 1992). Hubo una excepción dentro del grupo A, ya que integró al híbrido 'FHIA 03' (AABB), accesión que muestra características fenotípicas del subgrupo "Cavendish", como son: forma de racimo, presenta genoma AAA, pseudotallo color verde, altura media, al igual que las accesiones 'Robusta A' y 'Robusta B'. En otros estudios se encontraron resultados similares, ya que accesiones pertenecientes al subgrupo "Cavendish" mostraron similitud genética y conformaron un grupo filogenético bien definido (Bhat et al., 1995; Howell et al., 1994).

En cambio, en el grupo B se encontraron cultivares que presentan ambos genomas (A y B), los cuales pertenecen a diferentes subgrupos como "Plantain" ('Macho'), "Cavendish" ('Valery' y 'Rambao') y "Red" ('Morado' y 'Norteño'), cuyas características morfológicas en altura y color del pseudotallo, forma del racimo y tipo de fruta, son diversas (Daniells et al., 2001). Además, en este grupo se ubicaron los híbridos 'FHIA 01' (AAAB), 'FHIA 20' (AAAB), 'FHIA 21' (AAAB) y 'SH-3640' (AAAB). Este grupo se formó con accesiones que presentan características afines, como porte alto y pseudotallo delgado. Los híbridos 'FHIA 01', 'FHIA 20' y 'FHIA 21' presentan resistencia a Sigatoka negra. Las accesiones 'Valery' y 'Rambao' pertenecientes al grupo B, con genoma AAA del subgrupo "Cavendish", no se agruparon con las demás accesiones con genoma AAA, debido a que su morfología es de porte más alto, con pseudotallo más delgado (Daniells et al., 2001), al igual de las demás accesiones pertenecientes a este grupo. En otros estudios han reportado grupos filogenéticos formados por accesiones triploides AAA y AAB, así como algunos tetraploides AAAA, AABB y AAAB (Kaemmer et al., 1992; Ude et al., 2002; Howell et al., 1994; Bhat et al., 1995). 
En este estudio las accesiones 'Manzano' y 'Yangambi $\mathrm{km} \mathrm{5'}$ no mostraron similitud genética con el resto de las accesiones analizadas, por lo que no se ubicaron en ninguno de los dos grupos antes mencionados (Figura 2). Esto se debió a que entre las accesiones seleccionadas, únicamente estos cultivares pertenecen a otros subgrupos, según su caracterización morfológica (Daniells et al., 2001). Esto evidencia que los marcadores RAPD sirven para precisar la clasificación morfológica. Para el caso de 'Manzano' que pertenece al subgrupo “Silk”, la fruta se consume en fresco, presenta tolerancia a Sigatoka negra y susceptibilidad al mal de Panamá (Fusarium oxysporum f.sp. cubense W.C. Snyder \& H. N. Hansen), mientras que la accesión 'Yangambi $\mathrm{km} \mathrm{5}$ ' pertenece al subgrupo "Ibota", se usa como postre y presenta alta resistencia a Sigatoka negra (Daniells et al., 2001).

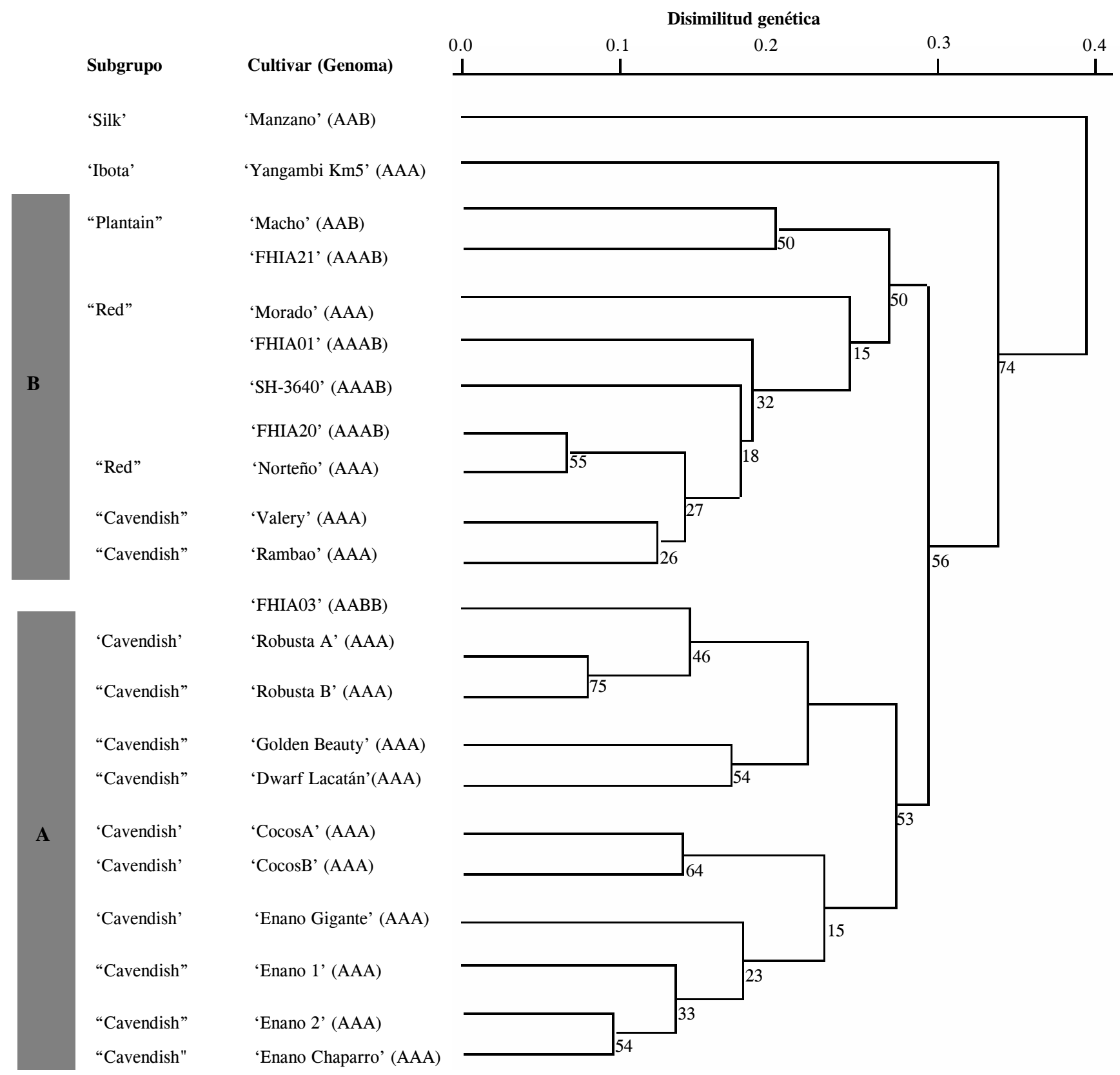

Figura 2. Dendrograma generado de 22 accesiones de bananos y plátanos basado sobre el análisis de 83 marcadores RAPD. La escala de disimilitud está en la parte superior, de 0.0 a 0.4. A la izquierda (entre paréntesis) se muestra el genoma y nombre de la accesión. Números bajo los nodos representan un valor generado mediante 3000 remuestreos. Las barras marcadas con A y B indican los dos grupos generados. 
Los resultados también muestran que los marcadores RAPD pueden usarse para identificar cultivares comerciales e híbridos de Musa, y demuestran que la mayoría de cultivares del subgrupo "Cavendish" forman un grupo por sus características moleculares, y que las accesiones pertenecientes a otros subgrupos fueron genéticamente distintos, como demostraron otros investigadores en otros bancos de germoplasma (Kaemmer et al., 1992; Howell et al., 1994; Bhat et al., 1995; Ude et al., 2003). La aplicación de esta técnica molecular es más confiable que la que se basa en características morfológicas, ya que no interactúa con el ambiente y permite eliminar la confusión asociada con la identidad entre cultivares que comparten características fenotípicas

\section{CONCLUSIONES}

En este estudio se demostró que el uso de marcadores RAPD es una herramienta útil para caracterizar la diversidad genética entre las 22 accesiones de plátano, banano e híbridos con diferente genoma, y tales marcadores coincidieron con la clasificación morfológica existente. El dendrograma generado mostró que el grupo A comprendió bananos del subgrupo "Cavendish" y al híbrido 'FHIA 03', mientras que en el grupo B se ubicaron cultivares del subgrupo "Cavendish", "Plantain", "Red" y los híbridos 'FHIA 01', 'FHIA 20', 'FHIA 21' y 'SH3640'. Dos accesiones, 'Manzano' y 'Yangambi km 5' no pudieron agruparse debido a que pertenecen a los subgrupos "Silk" e "Ibota", respectivamente, que son distintos morfológicamente del resto de las accesiones analizadas.

\section{BIBLIOGRAFÍA}

Avise J C (1994) Molecular Markers, Natural History and Evolution. Chapman and Hall, New York, NY. 511 p.

Bhat K, R Jarret, R Rana (1995) DNA profiling of banana and plantain cultivars using random amplified polymorphic DNA (RAPD) and restriction fragment length polymorphism (RFLP) markers. Electrophoresis 16:1736-1745.

Crouch H, J Crouch, R Jarret, P Cregan, R Ortiz (1998) Segregation at microsatellite loci in haploid and diploid gametes of Musa. Crop Sci. 38:211-217.

Damasco O, G Graham, R Henry, S Adkins, M Smith, I Godwin (1996) Random amplified polymorphic DNA (RAPD) detection of dwarf off-types in micropropagated "Cavendish" (Musa spp. AAA) bananas. Plant Cell Rep. 16:118-123.

Daniells J, C Jenny, D Karamura, K Tomekpe (2001) Musalogue: A Catalogue of Musa Germplasm. Diversity in Genus Musa. E Arnaud, S Sharrock (eds). International Network for the
Improvement of Banana and Plantain. Montpellier, France. $123 \mathrm{p}$.

Doyle J J, J Doyle (1990) Isolation of plant DNA from fresh tissue. Focus 12:13-15

Grapin A, J L Noyer, F Carreel, D Dambler, F C Baurens, C Lanaud, P J L Lagoda (1998) Diploid Musa acuminata genetic diversity assayed with sequence tagged microsatellite sites. Electrophoresis 19:1374-1380.

Howell E, J Newbury, R Swennen, L Withers, B Ford-Lloyd (1994) The use of RAPD for identifying and classifying Musa germplasm. Genome 37:328-332.

IPGRI-INIBAP-CIRAD (1996) Descriptors for Banana (Musa spp.). Roma, Italy. $59 \mathrm{p}$.

Kaemmer D, R Afza, K Weising, G Kahl, F Novak (1992) Oligonucleotide and amplification fingerprinting of wild species and cultivars of banana (Musa spp.). Bio/Technology 10:10301035.

Nei M, W H Li (1979) Mathematical model for the studying genetic variation in terms of restriction endonucleases. Proc. Natl. Acad. Sci. (USA) 76:5269-5273.

Ortiz R (1995) Musa genetics. In: Bananas and Plantains. S Gowen (ed). Chapman and Hall, London pp: 84-109.

Ortiz R, D Vuylsteke (1996) Recent advances in Musa genetics, breeding and biotechnology. Plant Breed. Abst. 66:1355-1363.

Pillay M, D C Nwakanma, A Tenkuano (2000) Identification of RAPD markers linked to A and B genome sequence in Musa L. Genome 43:763-767.

Rout G R, S Samantaray, P Das (2000) Biotechnology of the bananas: A review of recent progress. Plant Biol. 2:512-524.

Simmonds N (1962) The evolution of the bananas. Tropical Science Series Longman, Group UK Ltd, London. $170 \mathrm{p}$.

Simmonds N, K Shepherd (1955) Taxonomy and origins of cultivated bananas. Bot. J. Linn. Soc. (London) 55:302-312.

S-Plus (1997) S-Plus User's Guide version 4.0. Seattle: Math Soft. 525 p.

Staub J E, F Serquen, M Gupta (1996) Genetic markers, map construction, and their application in plant breeding. HortScience 31:729-740.

Swennen R, D Vuylsteke (1987) Morphological taxonomy of plantains (Musa cultivars $\mathrm{AAB}$ ) in West Africa. In: Banana and Plantain Breeding Strategies. G J Persley, E A De Langhe (eds). Proc. Workshop. Cairns, Australia, Oct. 1986. pp:165-171.

Ude G, M Pillay, D Nwakanma, A Tenkouano (2002) Genetic diversity in Musa acuminata Colla and Musa balbisiana Colla and some of their natural hybrids using AFLP markers. Theor. Appl. Genet. 104:1246-1252.

Ude G, M Pillay, E Ogundiwin, A Tenkouano (2003) Genetic diversity in an African plantain core collection using AFLP and RAPD markers. Theor. Appl. Genet. 107:248-255.

Vuylsteke D, R Ortiz, R Ferris, J Crouch (1997) Plantain improvement. Plant Breed. Rev. 14:267-320.

Williams J, A Kubelik, K Livak, J Rafalski, S Tingey (1990) DNA polymorphisms amplified by arbitrary primers are useful as genetic markers. Nuc. Ac. Res. 18:6531-6535.

Wong C, R Kiew, G Argent, O Set, O Kong Lee, Y Yuen (2002) Assessment of the validity of the sections in Musa (Musaceae) using AFLP. Ann. Bot. 90:231-238. 